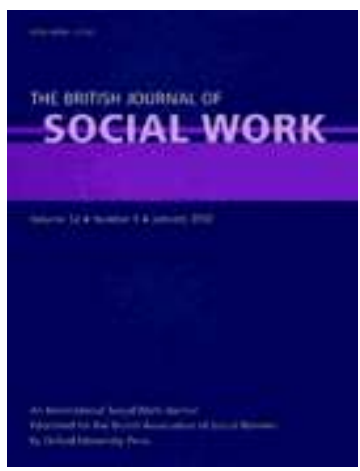

Draft Manuscript for Review. Please complete your review online at http://mc.manuscriptcentral.com/oup/bjsw

\title{
Unitary appreciative inquiry (UAI): A new approach for researching social work education and practice
}

\begin{tabular}{|r|l|}
\hline Journal: & The British Journal of Social Work \\
\hline Manuscript ID: & Draft \\
\hline Manuscript Type: & Original Article \\
\hline Keywords: & $\begin{array}{l}\text { Social work education, User led research, Values, Qualitative } \\
\text { methods, Practitioner research }\end{array}$ \\
\hline Subject Categories: & $\begin{array}{l}\text { Research Methods < Research and Evaluation, Education and } \\
\text { Training < Social Work and Social Workers }\end{array}$ \\
\hline
\end{tabular}

\section{SCHOLARONE Manuscripts}


Unitary appreciative inquiry (UAI): A new approach for researching social work education and practice

\begin{abstract}
:
This paper presents a methodological discussion of unitary appreciative inquiry (UAI). It considers its potential as a research tool, therapeutic intervention and an educative tool within social work practice and education due to its congruence with professional social work values. UAI seeks to gain rich and deep insight, understanding and knowledge of an experience from the person themselves. Participants are recognised as the expert of their own experience and power is shared through participatory and appreciative approaches. The aim is for participants to benefit directly from the research process as they are supported to express, analyse and reflect on their experience and to make changes which could improve their lives. Creative media such as music, art, creative writing and digital stories are used to facilitate expression and analysis. UAI seeks a synoptic perspective when viewing the wide range of data that has been generated within a research inquiry. Instead of analysing as separate parts, this is viewed as a whole and distilled to create a snapshot which seeks to capture the whole person and their experience. Insight gained from the presentation of research findings can provide a catalyst from which others can reflect, analyse and evaluate their own practice.
\end{abstract}

\title{
Key words:
}

Methodology, whole person, unitary appreciative inquiry, participatory, emancipatory, social work education, four types of knowing, values. 
Intro

This paper presents an overview of unitary appreciative inquiry drawing on examples from my own research and wider literature. It considers its potential as a research tool, therapeutic intervention and an educative tool within social work practice and education. The social work profession is guided by a set of professional values. In the UK, these are identified as the need to have 'respect for each person as an individual; to recognise and facilitate each person's use of language and form of communication; to value, recognise and respect the diversity, expertise and experience of individuals, families, carers, groups and communities; to maintain trust and confidence and to make use of strategies to challenge discrimination, disadvantage and other forms of inequality (National Occupational Standards 2002). These place as much emphasis on how we work with people as on what work we do. Research methods within social care should seek to emulate these professional values and best practice. This paper explores the potential of UAI to provide a research method which is underpinned by this set of professional values.

There are a number of factors explored in this paper which demonstrate the congruence between the principles of UAI and the values guiding social work education and practice. These are in relation to the research process itself and the insight, understanding and knowledge which can be generated through a unitary appreciative inquiry. These can be summarised as follows:

- The approach seeks to gain rich and deep insight, understanding and knowledge from the person themselves of a particular experience or context. 
- It reflects anti-oppressive principles as participants are recognised as the expert of their own experience and power is shared through participatory and appreciative approaches

- Participants are enabled to express themselves in creative ways, respecting their choice of language and forms of expression

- The emancipatory objectives of UAI enable the participants to benefit directly from the research process. They are supported to express, analyse and reflect on their experience and to make changes which could improve their lives.

- Insight, understanding and knowledge generated by the research can be disseminated in a variety of creative forms making it accessible to a wider audience.

- Insight gained from the presentation of research findings can provide a catalyst from which others can reflect, analyse and evaluate legislation, policy and practice.

Each of these elements is explored within this paper. The discussion is informed by my own Doctoral studies concerning the student experience and the impact of social work education on a person's beliefs, values and behaviour. The study sought to illuminate the impact of social work education on the whole person (not just aspects of self such as student or social worker). It identified a significant impact on the person themselves, their relationships with others and the way they viewed the world. Participants talked of 'seeing oppression everywhere', experiencing changes to their value base, developing different or broader perspectives, being more knowledgeable and recognising the impact of their upbringing, background and culture on the views and beliefs they held. They shared experiences and provided insight into their 
experience of undergraduate qualifying social work education which they described as exhausting, draining, emotionally testing; frustrating; stressful; difficult, challenging; exciting, inspiring, humbling and life changing. All of these insights were gained through a unitary appreciative inquiry.

Fundamental to the methodological approach are its emancipatory and transformative qualities. Social work seeks to 'promote social change, problem solving in human relationships and the empowerment and liberation of people to enhance well-being' (IASSW and IFSW 2001). W Richard Cowling developed UAI as an approach that could work both as a research tool to gain insight into a particular experience and a therapeutic intervention which could make the process as valuable as possible for the participants. Participants can engage in a 'knowing participation in change' (Cowling and Repede 2010 p73). When exploring the principles of UAI, this paper will discuss how this can be achieved.

Rather than as a therapeutic intervention, my own research study demonstrated its duality as a research technique which also served as an educative tool. It was used to research the experiences of social work students on the undergraduate social work programme for which I am a lecturer. I chose the approach because I wanted to maintain the educative qualities of my relationship with the student participants and to ensure that their participation was of direct benefit to them. This was achieved through the participatory, empowering and collaborative methods of UAI which support the participants to express and seek an understanding of their experiences and to critically reflect on their learning. 
What is unitary appreciative inquiry (UAI)?

UAI has emerged over the past decade for use primarily within mental health nursing research and practice. The use of UAI so far has been limited to studies and papers by its author (Cowling 2000, 2001, 2004a, 2004b, 2005, 2010), and a small number of mainly health related research studies (Kemp 2004, Talley 2004, Cox 2004, Talley et al 2005, Alligood 2008, Rushing 2008, Repede 2009). It was developed by Cowling who sought an approach which recognised 'human wholeness and uniqueness' (Cowling 2004 p202). He argues that this is often neglected when 'human phenomena are 'clinicalized' with an over-emphasis on diagnostic representations' (Cowling 2001 p32). .

UAI is based on Martha Rogers' science of unitary human beings; a conceptual system for nursing which recognises the integrality ( sic) of humans and their environment' (1990 p109). It argues that rather than inter-related parts, humans and their environment are elements of the same phenomena and as such cannot be fully understood in isolation (Rogers 1990). The main principle from Martha Rogers' work which underpins UAI is the belief in the' irreducible, indivisible nature of human beings' (Rogers1990 p109). In attempting to view the person as a whole and within the context of their environment, Rogers and subsequently Cowling through the development of UAI, seeks to capture the person's 'wholeness'.

By understanding and appreciating life patterns, wholeness and uniqueness, practitioners can seek to improve 'the lives of individuals, families, groups and communities' (Cowling 2005 p94). Reflection on these representations and patterns 'can provide a way of understanding human life, conditions and situations' (Cowling 
2001 p35) and as such, can also be used to inform our understanding of a particular context. As Rushing (2008) suggests, reality can be perceived from a wider perspective when aspects of a person's experience are explored that others may have considered to be disparate, dissimilar or unrelated.

Rogers (1990) argued that such insight can lead to increased self awareness for both practitioners and patients. Cowling and Repede (2010 p73) describe UAI as having the goal of transformation and emancipation for those involved. In a practice, research or educational context, it can be used to enable all involved including the participants and those viewing the research findings to develop their own propositional and practical knowledge; drawing conclusions from what they have learnt and acting on this knowledge to improve their lives or their practice.

\section{How does UAI work?}

UAI seeks a synoptic perspective when viewing data that has been generated within a research project. The aim is to generate a range of data which instead of analysing as separate parts, is viewed as a whole (Cowling and Repede 2010). The synopsis of the findings is used to see if a pattern emerges which 'reflects the wholeness, uniqueness and essence of human life' (Cowling 2001 p36). This synopsis is presented in the form of a unitary appreciative profile of the person, situation or context.

The aim of the profile is for its use by practitioners (or researchers and educators) to develop their own practice and for participants to "know their life pattern and to use these skills to transform their lives in meaningful ways' (Cowling 2004 p212). The process of creating a unitary appreciative profile is as important in seeking insight and 
transformation as the profile itself. Whilst much of Cowling's work has been to explore the experience of despair, other researchers have used UAI to explore experiences and life patterns and to promote personal transformation for people within the context of teenage pregnancy and motherhood (Talley 2004); professional caregiver despair (Cox 2004); undertaking a drug and alcohol 12 step programme (Rushing 2008); experiencing spinal cord injury (Alligood 2008); and participatory dreaming (Repede 2009). One study developed a unitary appreciative profile of a town rather than of a person or group (Talley et al $2005 \mathrm{p} 27)$. The profile aimed to capture the essence and spirit of the community; 'a living portrait' which moved beyond facts and figures. They achieved this by physically exploring the town and in addition to noting their physical environment also considered the spirit, flow, experiences, expectations, attitudes, values, aesthetics, rhythms - movement, sense of time, hopes and fears and relationships of the town and its people. This was distilled to create a 'snapshot'. When presenting this to others, sights, sounds, tastes, song and story were used rather than facts and figures to convey a snapshot that represented the wholeness of the town.

The distinctive feature of the profiles created within each of the research inquiries is the use of creativity e.g. film, music, storytelling and poetry, to express, capture and represent wholeness. Capturing the essence moves beyond facts and figures and what is immediately apparent. It seeks to surface themes, links and patterns and to create a representation of something that is recognised as in constant flux and change. In seeking to capture and represent this wholeness, it seeks to generate a range of data that represents different types of knowing. 


\section{Four types of knowing}

Cowling (2004) adopts the distinction Heron (1996) makes between four different types of knowing that can be informed by research inquiry. These are experiential; presentational; propositional and practical knowing. Several of the unitary appreciative inquiries previously mentioned have maintained this distinction. More recently however, Cowling and Repede (2010) have challenged researchers to refrain from the categorisation of representations but to seek ways of conveying the interrelatedness of the forms of knowing in the presentation of findings. The following explains the four types and considers how more holistic, interconnected, synoptic representations can be achieved.

The first of Heron's (1996) four types of knowing is experiential. This is gained through direct contact with the person involved and requires empathy and resonance to develop a perception of the person's experience (Cowling 2004). Heron (1996 p52) suggests that developing experiential knowledge involves the researcher 'imaging and feeling the presence of some energy, entity, person, place, process or thing'. Cowling (2004) suggests that this may take the form of conversations, discussions, interviews, focus groups and observations. Talley (2004) achieves this through ongoing dialogue over a six week period. Rushing (2008) and Alligood (2008) interview individual participants. I utilised individual interviews and a group workshop. The process is not restricted to dialogical engagement but can include any process which enables the researcher to generate experiential knowledge.

Presentational knowledge can emerge from experiential knowledge through the development of representations of the person to express the meaning and significance 
of the experience (Heron 1996). Heron suggests that representations can be used for both expression and explanation. In both cooperative inquiry and unitary appreciative inquiry, these representations can be through imagery, music, storytelling, poetry or any other media or metaphor. Cowling (2004b, 2005) adopts this in different studies both by developing pattern profiles himself as an interpretation of the person's experience and by enabling the person or group to do these themselves as an expression of their experience. Rushing (2008) uses different styles of poetic writing to present the experiences of serenity in recovery from alcohol and drug addiction whereas Alligood (2008) creates individual biographical stories to represent individual experience of spinal cord injury and a fictional narrative story to represent the pattern profile. Such expressions can stand alone as the creation of presentational knowledge, a type of knowing in its own right, without the need for interpretation, analysis or words. Heron (1996) suggests that the observer can develop an intuitive grasp of their significance. Cowling (2005) describes this as appreciation. It embraces a type of knowing which is distinct from critical knowing in that it is based on affirmation, trust, belief and conviction (Cowling 2001).

Propositional knowing is the expression of statements which draw on ideas and theories generated from the knowledge gained so far (Heron 1996). Whilst a unitary appreciative profile in UAI may incorporate specific or unique representations of each person or group; themes, theories and reflections can be generated by the participants including the researcher which may have meaning for others and may in turn generate further reflections and insights. It can form the basis of factual claims 'which are applicable in more global situations' (Talley et al 2005 p32). Heron (1996) adapts his pyramid model of the four types of knowing grounded in experiential knowing and 
developing up through presentational, propositional and then practical knowing to one of a circuit model where deeper and richer types of knowledge emerge as one continues to inform another. This resonates with Cowling and Repede's (2010) call for a more synoptic representation of the different forms of knowing to represent wholeness.

The final type of knowing identified in Heron's circuit model is practical knowing. In many ways this is the type of knowing which defines action research and UAI as it identifies the practice, skills and competence required to act on the other forms of knowledge. It is the 'action' of the research that enables participants to actualise change. Cowling (2001) argues that such action emerges from the unitary appreciative process in the way it seeks to understand (a particular condition or phenomena); the use of unitary consciousness and 'the development of one's self as an instrument of appreciation' (p36-7). In relation to a social work context, action could be by the participants (including the researcher) in terms of changes they chose to make to their lives following reflections and conclusions they have made during the research process and wider afield as the research findings provide a catalyst for others from which to reflect and make changes relevant to them.

\section{My own study}

In my own research study a number of tools were used to gain as close a picture as possible of the participants' experience and to help them to express and reflect on what could be learnt from this. This involved generating different types of knowledge through verbal, written and visual expressions and interpretations of the participants' own experiences and life patterns in the context of their social work education. This 
was achieved through conversations, one to one interviews, a group workshop and email exchanges.

The one to one interviews focussed primarily on developing a perception of each individual's experience of learning within social work education and the impact of this on their lives. Questions were guided by three themes: gaining a sense of the person; exploring their perceptions of the impact of their social work education on themselves and their reflections and perceptions on the implications of this impact. The workshop used a range of techniques to enable the participants to build on this. They shared representations of their experience by identifying metaphors, imagery and / or music which they felt represented the impact for them. One participant for example shared a piece of music, The Streets: It's not that easy. She described the album itself as a soundtrack to her three years but also reflected on the resonance for her of the lyrics. 'He lays it bare - is honest. He thanks everyone who has ever dissed (sic) him for giving him focus.' The process of explaining their choices and discussing the resonance for them facilitated the participants' critical reflection and surfaced links they had not otherwise considered.

The participants also created personal profiles which represented their sense of self (what makes you, you?). They developed the profiles through the use of 'mind maps' which focussed on three stages. The first was their identity and sense of self e.g. their likes, dislikes, social status, relationships, background and any other aspect they considered as significant. They then focussed on the relationship and connections between this identity and sense of self and their beliefs, values and behaviours e.g. the impact of parental influences, religious beliefs, childhood experiences and personal 
experiences. At the third stage, they considered how their social work education had informed, challenged or impacted on these. The participants shared their mind maps and supported each other to critically reflect and make sense of the connections. One participant identified his cultural beliefs and how these had been challenged by his social work education. His beliefs in relation to gender and sexuality for example had fundamentally changed as he described 'becoming more informed' and 'developing an understanding' which led to a more accepting viewpoint. This had a significant impact then on his cultural beliefs and family relationships as he sought to challenge views and behaviours of those around him. He reflected on the process of developing a view of the world that was congruent with his developing professional values and his cultural and religious beliefs. For him, this was reconciled by focussing on the shared values of respect for others. This resonated for other participants who recognised assumptions or beliefs they had held in relation to gender, age, race and disability.

All the data generated within the one to one interviews and the workshop was used to compile a unitary appreciative profile to represent the impact of social work education on a person's beliefs, values and behaviour and the impact that these changes can have on a person's life. This was distilled into a 10 minute digital story (series of images with an audio commentary) to convey the essence of this experience to others. The completed profile was used as a catalyst for further critical reflection by the participants and other social work students, practitioners and educators who have viewed it.

Discussion 
This paper started with the proposal that UAI could be a new approach for researching social work education and practice. There are a number of factors which inform this claim.

The methods are congruent with professional social work values which seek to place the person at the centre of any involvement, to recognise their expertise and to view each person as unique. The appreciative aspect of UAI involves replacing the notion of problem (typical in action research, participatory research and cooperative inquiry) with that of mystery, 'something to get caught up in' (Cowling 2005 p96); 'a miracle that can never be fully comprehended' (Cooperrider and Srivastva 1987 p2). Appreciative inquiries focus on what works rather than to problem solve. Participants themselves identify what is important and of value (Alligood 2008). This places the participants in a position of power as the approach aims to affirm and appreciate their experiences rather than criticise or show scepticism. It recognises the participant as the expert of their experience and places the researcher in the position of learner; the person who is seeking to understand and gain insight. UAI adopts what Kvale (1996) identifies as a traveller approach to research where the researcher listens to people's stories and uncovers their experiences, views and perspectives. In addition to discovering new knowledge, a potential outcome is that 'the traveller may change as well' (Kvale 1996 p4) making the researcher an active participant in the learning process.

This sharing of power is also achieved through participation. UAI methodology builds on frameworks used in participatory action research, in particular cooperative inquiry which was proposed by Heron in 1971 and subsequently developed by Heron and 
Reason (Heron 1996). It is based on the belief that self directed learning, autonomy, cooperation and reciprocal relations are fundamental in undertaking any research into the human condition which aims to result in personal and social transformation (Heron 1996). This aspect of a unitary appreciative inquiry is congruent with the professional values which inform social work practice but also of adult educational theorists such as Rogers (1969), Knowles (1984) and Mezirow and associates (1996) who argue that this is how adults learn.

The drive for research 'with' rather than research 'on' people is not only in relation to acknowledging the person's expertise but also in ensuring that the research process is of direct benefit for them. The emancipatory objectives of UAI enable participants to learn about their experiences and to identify changes they can make to improve their lives. It has potential for use as a model of intervention which can also be used by the researcher or practitioner to gain insight into the context in which the person lives. Working with a person or group to create a 'living portrait' or 'snapshot' of their experience can support the therapeutic as well as the educational process. It can facilitate expression, reflection, self appreciation and self awareness. Such outcomes could be argued as beneficial for participants within educational, health or social care settings.

Within professional education such as social work, there is an increasing emphasis on self and the need for the person to critically challenge their own beliefs, values and behaviours to align theirs with those of the profession. In my own study, the appreciative, participatory and emancipatory elements of UAI worked effectively as a tool to facilitate the student participants' critical reflection. It provided them with the 
opportunity to step back and recognise, express and explore their learning as a whole. The student participants described the process as having enabled them to recognise how much they had changed. It was part of their process of ending as they approached the end of their qualifying education; and provided a platform from which to share their experiences.

As with any method of intervention or research, there are pros and cons. It requires a skilful researcher or practitioner to facilitate this process and to enable the participants to express and analyse their experiences. Cowling places emphasis on the relationship between the researcher and the participants. He describes this as key to the process of UAI where interactivity is seen as 'a powerful force which can be used to benefit the research enterprise' (2001 p46). The potential of the approach to surface links and connections that the person had not otherwise considered, may be uncomfortable for those involved and would need to be managed effectively. The participants within my own research study were articulate, expressive and analytical students who were practiced in the skill of critical reflection. This will have affected the nature of the knowledge generated and the comfort of the participants in expressing it.

As with any methodological approach there are many ethical considerations. Seeking informed consent for participatory research approaches for example is difficult given the open ended nature of the inquiry and the inability to identify at the outset what the research process may specifically involve (Miller and Crabtree 1999, Holloway and Jefferson 2000, Malone 2003, Marshall and Rossman 2006). Familiarity between the researcher and the participants is also an issue I have given much consideration to. This is in relation to professional boundaries; insider research and potential power and 
influence over the research process. Whilst considerations for my own study are explored in more details elsewhere, it is important to emphasise the need to surface these issues and consider how they may enhance or negatively influence the research process and findings.

The use of creative media is also a factor that could be considered positively or negatively. There is limited literature relating to the use of creative arts and media by social work educators. Media such as fictional narratives (Rutten et al 2009) and classic literature (Turner 1991) have been used to facilitate the student's learning and to provide a catalyst for the student's critical reflection but these have both involved established works. There is more of a track record for using creative approaches within therapeutic practice. The aims of unitary appreciative inquiry and the development of presentational knowing is for the researcher or the participants to create representations or metaphors themselves, using any media as both a form of expression and analysis. Broadening the range of opportunities for expression and analysis may help participants find ways to express themselves more effectively. It could be of considerable benefit to those who are less able to express themselves verbally. Enabling a person to express and analyse experiences in a different way can be an effective catalyst for critical reflection and can facilitate transformative learning.

\section{Conclusion}

This paper has provided an overview of a unitary appreciative inquiry. As a new approach it is still evolving as new researchers provide their own interpretations and apply refinements as they implement UAI (Cowling and Repede 2010). The studies 
completed to date demonstrate the benefits of UAI in creating close representations of a person or group's experience and in generating new knowledge for more global situations. Findings from my own research study have led to fundamental changes in my own practice as an educator and the promotion of teaching, learning, assessment and support strategies which seek to enhance the learning experience for students by acknowledging the impact on self.

Participants in unitary appreciative inquiries have described feeling listened to and understood by the research process (Cowling 2004b) and describe the representations as 'personal, authentic and true' (Rushing 2008 p206). This makes it a useful tool for social work researchers seeking a method which is congruent with the values of the profession. Whilst respecting the individual, incorporating an anti-oppressive approach to research practice and ensuring a positive and valuable experience for the participants, it also provides a mechanism by which to seek meaningful insight and knowledge into a particular experience. Whilst primarily developed as a research method with therapeutic qualities, my own research study demonstrated its value as an educative tool in fostering critical reflection and transformative learning for student participants. As a new approach it requires more exploration and testing to evaluate its effectiveness in these areas but it certainly offers potential as a new method for researching social work education and social care practice. 


\title{
References
}

\begin{abstract}
Alligood, R 2008 Life Patterns of people with Spinal Cord Injury.
https://digarchive.library.vcu.edu/bitstream/10156/1954/1/alligoodrr_phd.pdf
\end{abstract}

Cooperrider, D. L.; Srivastva, S (1987); Appreciative Inquiry in Organizational Life; In: Research in organizational change and development. Vol. 1. US: Elsevier Science/JAI Press, 1987. pp. 129-169.

Cowling, W.R 2001 Unitary Appreciative Inquiry. Advances in Nursing Science, 23(4) $32-38$

Cowling, R 2004a Pattern, Participation, Praxis and Power in Unitary Appreciative Nursing Perspective. Advances in Nursing Science. 27(3): 202-214

Cowling, R 2004b Despair: A Unitary Appreciative Inquiry. Advances in Nursing Science. 27(4): 287-300

Cowling, R 2005 Despairing Women and Healing Outcomes: A Unitary Appreciative Inquiry. Advances in Nursing Science. 27(4): 287-300

Crabtree, B.F and Miller, W. L 1999 (Editors) Doing Qualitative Research (2 ${ }^{\text {nd }}$ edition) London: Sage 
Daarra, S 2008 Emotion Work and Ethics of Novice Insider Research. Journal of Research in Nursing 2008; Vol 13; 251-261

Heron, J (1996), Co-Operative Inquiry: Research into the Human Condition. London: Sage Publications.

Holloway, I (1997) Basic Concepts for Qualitative Research. Blackwell Science.

Oxford

Holloway, I and Todres, L (2003) The Status of Method: flexibility, consistency and coherence. Qualitative Research vol 3 (3): 345-357

Holloway, I and Wheeler, S (2009) Qualitative Research in Nursing and healthcare. Oxford, Blackwell (in press)

Knowles, M (1984) The Adult Learner: A Neglected Species. $3^{\text {rd }}$ ed Gulf Publishing

Kvale, S (1996) Interviews: An introduction to Qualitative Research Interviewing. Sage:London

Malone, S 2003 Ethics at home: informed consent in your own backyard. Qualitative Studies in Education, Nov-Dec 2003, Vol 16, No 6, 797-815 
Mercer, J 2007 the challenges of Insdier Educational Research in Educational Institutions: wielding a double edged sword and resolving delicate dilemmas. Oxford Review of Education February 2007, Vol 33, No 1, 1-17

Mezirow, J. (1996). Contemporary paradigms of learning. Adult Education Quarterly, 46(3), $158-172$

Potts, A 2008 Resarching Academic Staff: The case of colleges and Universities in Sikes, P and Potts, A 2008 Researching Education from the Inside: Investigations from within. London: Routledge

Reason, P 1994 Participation in Human Inquiry. London: Sage

Rogers, M 1990 Space Age Paradigm for New Frontiers in Nursing chapter in Parker, M.E Nursing Theories in Practice. National League for Nursing. New York

Rushing, A 2008 The Unitary Life Pattern of Persons Experiencing Serenity in Recovery From Alcohol and Drug Addiction. Advances in Nursing Science. July / September 08. Vol 31 Issue 3 pp198-210

Rutten, K, Mottart, A and Soetaert, R 2009 Narrative and Rhetoric in Social Work Education. British Journal of Social Work 2009 1-16

Sikes, P and Potts, A 2008 Researching Education from the Inside: Investigations from within. London: Routledge 
Skills for Care 2002 Statement of Expectations of People using services and their carers Accessed http://www.niscc.info/content/uploads/downloads/workforce_dev/NOS_health_social/ $\underline{\text { Statement_expectations.pdf }}$

Talley, B 2004 Early motherhood: Having two or more children while still a teen. Accessed 6/10/09 at http://apha.confex.com/apha/132am/techprogram/paper_87624.htm

Talley, B, Rushing, A, Gee, R 2005 Community assessment using Cowling's unitary appreciative inquiry: A beginning exploration. Visions: Journal of Rogerian Nursing Science vol 13, no 1

TOPSS UK Partnership May 2002 National Occupational Standards for Social Work. Accessed 15/2/10 at http://www.skillsforcare.org.uk/developing_skills/National_Occupational_Standards/s $\underline{\text { ocial_work.aspx }}$

Turner, M 1991 Literature in Social Work: An exploration of how literature informs Social Work in a way Social Sciences cannot. British Journal of Social Work, 1991, $21,229-243$ 